Supporting Information

for

\title{
Cyanopyridine Based Bipolar Host Materials for Green Electrophosphorescence with Extremely Low Turn-on Voltages and High Power Efficiencies
}

\author{
Wei Li, Jiuyan Li,* Di Liu, Deli Li, Fang Wang \\ State Key Laboratory of Fine Chemicals, College of Chemical Engineering, Dalian University of \\ Technology, 2 Linggong Road, Dalian, 116024, China. \\ E-mail: jiuyanli@dlut.edu.cn
}



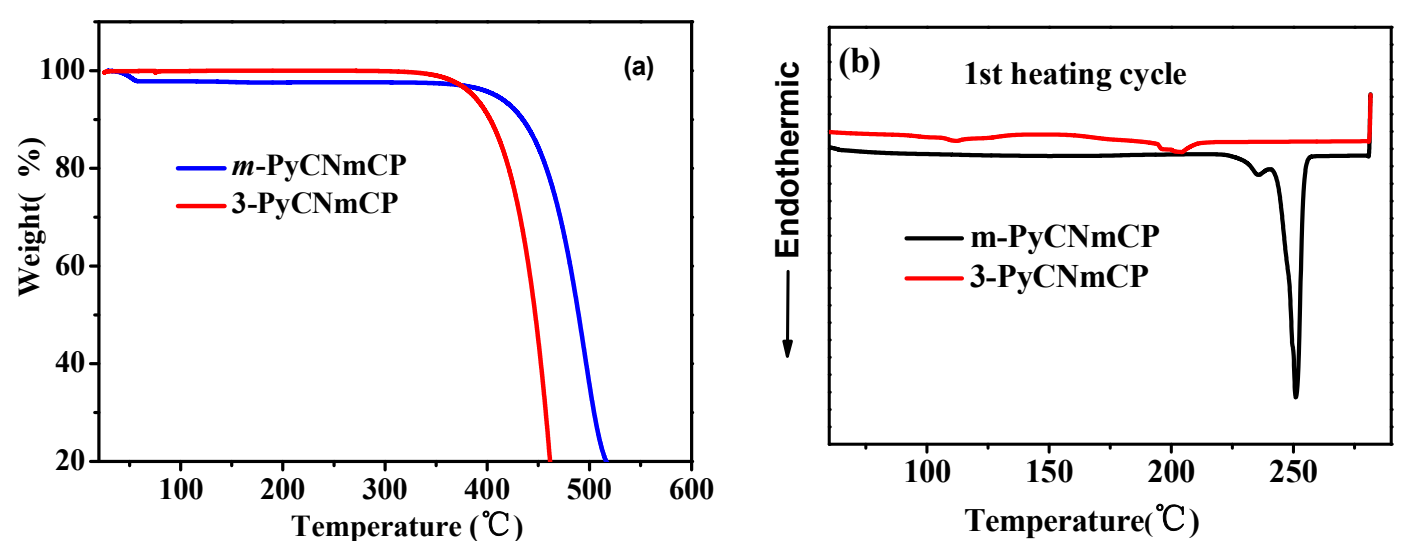

Figure S1 (a) TGA thermograms and (b) DSC curves during the $1^{\text {st }}$ heating cycle for $m$-PyCNmCP and 3-PyCNmCP, recorded at a heating rate of $10{ }^{\circ} \mathrm{C} \mathrm{min}^{-1}$.
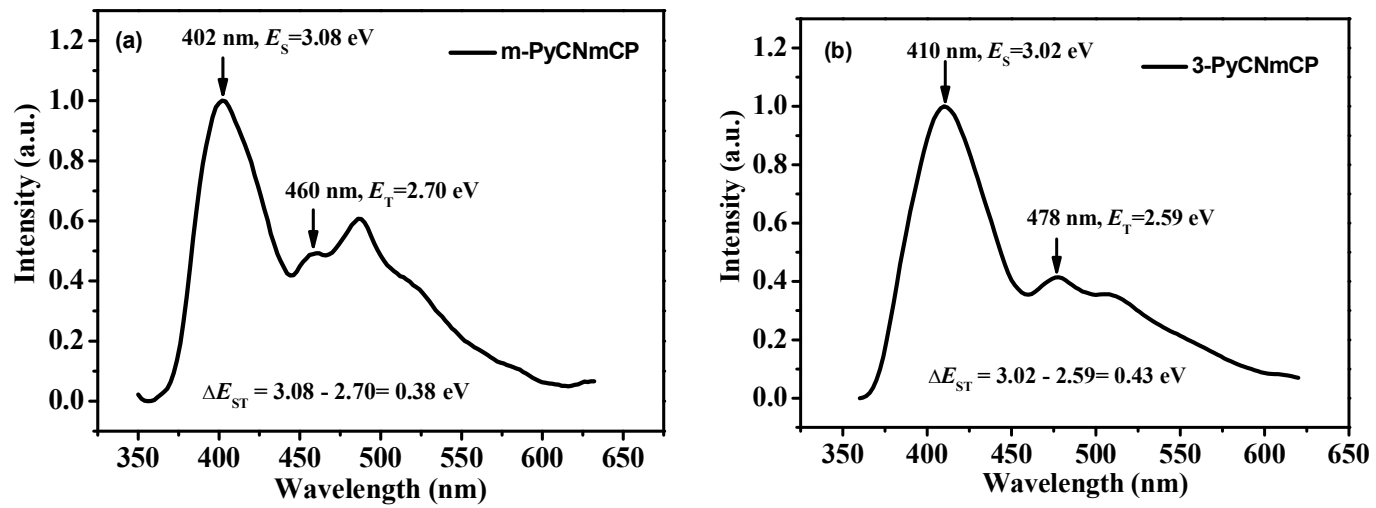

Figure S2 The LT PL spectra of $m$-PyCNmCP (a) and 3-PyCNmCP (b) films. The singlet and triplet energies and $\Delta E_{\mathrm{ST}}$ are indicated in the figures. 

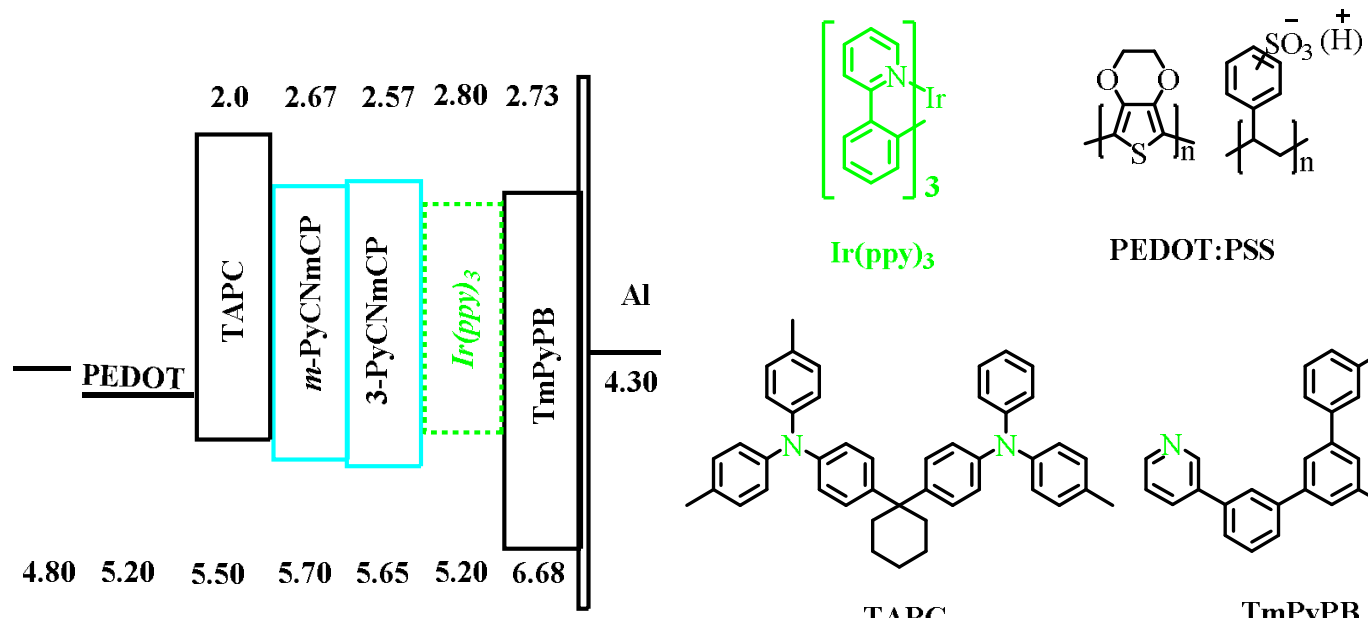

$\operatorname{Ir}(\mathrm{ppy})_{3}$

PEDOT:PSS
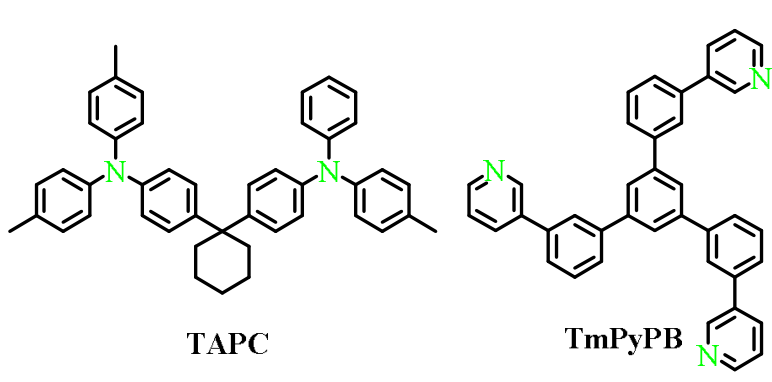

Figure S3

Chemical structures of related materials and energy level diagrams for the single carrier devices and green PhOLEDs.
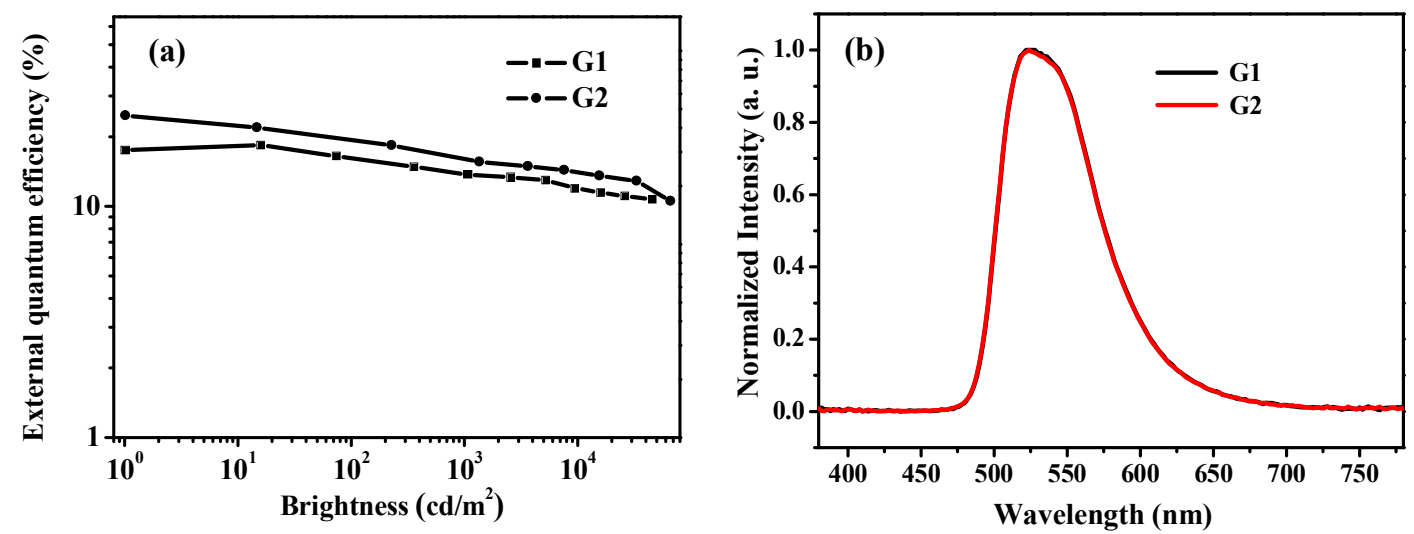

Figure S4 (a) The external quantum efficiency-brightness curves and (b) EL spectra of green PhOLEDs G1 and G2. 


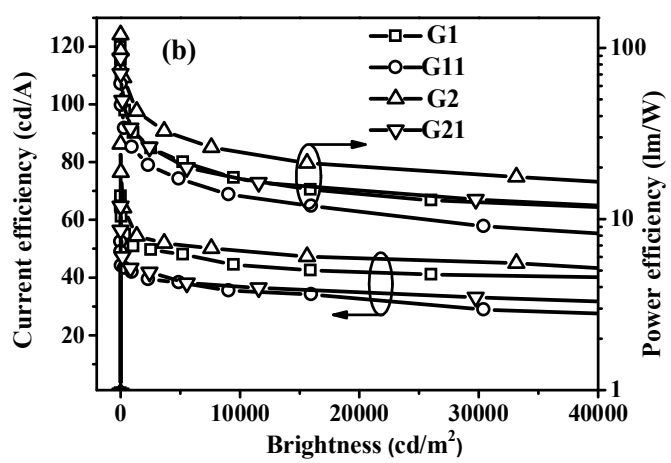

Figure S5 The efficiencies comparison for $m$-PyCNmCP hosted devices G11 (control device, 6 wt\%) and G1, and 3-PyCNmCP hosted G21 (control device, 6 wt\%) and G2.

Table S1 EL data comparison for green devices G1, G2, and control devices G11 and G21.

\begin{tabular}{|c|c|c|c|c|c|c|c|}
\hline Devices & Host & $\begin{array}{c}\text { Doping } \\
\text { level } \\
(\mathrm{wt} \%)\end{array}$ & $\begin{array}{l}V_{\text {on }} \\
(\mathrm{V})\end{array}$ & $\begin{array}{c}L_{\max } \\
\left(\mathrm{cd} \mathrm{m}^{-2}\right)\end{array}$ & $\begin{array}{c}\eta_{\mathrm{c}}{ }^{\mathrm{a}} \\
\left(\mathrm{cd} \mathrm{A}^{-1}\right)\end{array}$ & 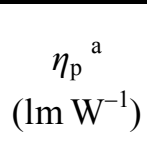 & $\begin{array}{l}\eta_{\text {ext }}{ }^{\mathrm{a}} \\
(\%)\end{array}$ \\
\hline G1 & \multirow{2}{*}{$m$-PyCNmCP } & 10 & 2.01 & 45510 & $\begin{array}{l}68.2 \\
60.3 \\
52.7\end{array}$ & $\begin{array}{c}101.4 \\
62.2 \\
32.7\end{array}$ & $\begin{array}{c}18.4 \\
16.3 \\
14.2\end{array}$ \\
\hline G11 & & 6 & 2.22 & 49656 & $\begin{array}{l}52.4 \\
43.7 \\
40.8\end{array}$ & $\begin{array}{l}74.2 \\
39.6 \\
23.2\end{array}$ & $\begin{array}{l}14.8, \\
12.4 \\
11.6\end{array}$ \\
\hline G2 & 2 Dr & 10 & 2.27 & 66440 & $\begin{array}{l}86.2 \\
84.9 \\
58.5\end{array}$ & $\begin{array}{c}119.3 \\
71.4 \\
54.5\end{array}$ & $\begin{array}{c}24.7 \\
24.3, \\
16.8\end{array}$ \\
\hline G21 & 3-PYCNmCP & 6 & 2.33 & 64552 & $\begin{array}{l}64.8 \\
51.4, \\
42.2\end{array}$ & $\begin{array}{l}87.3 \\
59.4 \\
29.9\end{array}$ & $\begin{array}{l}18.9, \\
15.0 \\
12.3\end{array}$ \\
\hline
\end{tabular}

${ }^{a}$ Order of measured values: maximum, then at 100 and $1000 \mathrm{~cd} \mathrm{~m}^{-2}$. 